\title{
Eclampsia and Pregnancy Outcome at Jos University Teaching Hospital, Jos, Plateau State, Nigeria
}

\author{
Anyaka Charles, Pam Victor, Karshima Jonathan, Pam Ishaya \\ Department of Obstetrics and Gynaecology, University of Jos / Jos University Teaching Hospital, Jos, Nigeria
}

Email address:

charlesanyaka@yahoo.com (A. Charles)

\section{To cite this article:}

Anyaka Charles, Pam Victor, Karshima Jonathan, Pam Ishaya. Eclampsia and Pregnancy Outcome at Jos University Teaching Hospital, Jos, Plateau State, Nigeria. Journal of Gynecology and Obstetrics. Vol. 5, No. 4, 2017, pp. 46-49. doi: 10.11648/j.jgo.20170504.11

Received: May 5, 2017; Accepted: May 15, 2017; Published: July 13, 2017

\begin{abstract}
Context: Eclampsia contributes significantly to maternal and perinatal mortalities globally. The objective of this study is to review the maternal and foetal outcome of eclampsia in Jos University Teaching Hospital (JUTH), Jos Plateau, Nigeria. Study design: A retrospective study that reviewed records from labour ward and the Medical Records Department, of cases of eclampsia managed at JUTH over a 9 year period from 1st January 2008-31st December, 2016. Results: There were 145 cases of eclampsia out of a total of 17,169 deliveries within the study period, giving a prevalence of $0.84 \%$. It was most common, $22(24.8 \%)$, in the 25-29 year age group. The nulliparous women, $58(40 \%)$ were more commonly affected. The prevalence was higher in the un-booked patients $86(59.3 \%)$, and antepartum eclampsia was the commonest type133 $(91.7 \%)$. Headache with blurring of vision $106(73.1 \%)$ was the commonest symptom. The case fatality rate was $5.5 \%$, low birth weight was seen in 78 (53.8\%) while Perinatal death was 18 (12.4\%) Conclusion: Eclampsia occurred mainly in un-booked and primigravid patients in this study. Early registration of pregnant women, especially primigravida, in health facilities for effective antenatal care and supervised hospital delivery will significantly reduce the prevalence and complications of eclampsia.
\end{abstract}

Keywords: Eclampsia, Pregnancy Outcome, JUTH, Jos Nigeria

\section{Introduction}

Pre-eclampsia is one of the most common complications of pregnancy and continues to be a leading cause of death and disability globally [1]. Pre-eclampsia is characterized by new onset of hypertension and proteinuria after 20 weeks gestation [2]. It may progress to eclampsia; a potentially lethal complication characterized by convulsions requiring an emergency response [3]. Eclampsia which is often considered a complication of severe pre-eclampsia, is commonly defined as new onset of grand mal seizures and/or unexplained coma during pregnancy or post partum in a woman with signs and symptoms of pre-eclampsia in the absence of any neurological disease $[4,5]$.

There are variations in the reported incidence of eclampsia in different parts of Nigeria. The reported incidence of eclampsia was $1.6 \%$ in Jos [6], $1.2 \%$ in Kano [7], $4.29 \%$ in Sokoto [8], 5.7\% in Nguru [9], 0.91\% in Nnewi [10], 0.80\% in Aba [11], 2.52\% in Irrua [12], 0.91\% in Ile-Ife [13].

The World Health Organization estimates that $14 \%$ of all maternal deaths result from the hypertensive disorders of pregnancy (HDP); it is also associated with a high risk of newborn death [1]. Most of the over half a million maternal deaths that occur annually are in developing countries like Nigeria [14]. Nigeria and India are estimated to account for over one third of all maternal deaths worldwide in 2015, with an approximate 58,000 maternal deaths (19\%) and 45,000 maternal deaths (15\%) respectively. Eighteen other countries, all in sub-Saharan Africa, are estimated to have very high maternal mortality ratio (MMR) in 2015, including Nigeria (814) and Malawi (634) [15]. Nigeria also has a high prevalence of pre-eclampsia and eclampsia of between $2 \%$ to $16.7 \%$ [16]. Worldwide eclampsia and preeclampsia account for about 63000 maternal deaths annually [17].

Eclampsia contributes $31.3 \%-43.1 \%$ to maternal death in the Northern part of the country with maternal mortality ratio of 1,200 per 100,000 live births [9, 18], whereas in the South West and Niger-Delta region of the country with much lower MMR of 500/ 100,000 live births, eclampsia accounts for $27.5 \%$ to $40 \%$ of deaths [19]. The high maternal morbidity and 
mortality associated with this condition in this environment result from low utilization of health facilities and the poor quality of antenatal care in most of the referring health facilities. This was evidenced by self referral in patients who delivered at home or referral from traditional birth attendants (TBA) and faith based maternity facilities where basic screening tests could not be carried out [20]. Even in tertiary health facilities in Nigeria, case fatality rate is still significantly higher compared with developed settings where high profile life support care is readily available [21].

Several theories exist on the pathogenesis of preeclampsia, but at present, it is suggested that the placenta is the primary agent in the development of preeclampsia, hence, removal of the placenta (by termination of the pregnancy is the sole method of treating the condition [22]. Studies continue to suggest the increasing burden of HDP around the world making it a growing public health problem [23]

It should be noted that the adverse effects of preeclampsia and eclampsia are not only limited to the mother but also to the foetus with several complications ranging from intra-uterine growth restriction to intra-uterine foetal death [24]

Eclampsia is a very serious but preventable complication of pregnancy responsible for high maternal and perinatal mortality. So this study was conducted to see different factors associated with eclampsia.

\section{Methodology}

The study was carried out in Jos, Plateau State, North Central Nigeria.

It was a descriptive cross-sectional retrospective 9 year study, which was carried out among women with eclampsia in the Department of Obstetrics and Gynaecology, Jos University Teaching Hospital (JUTH), Jos, Plateau State from January 2008 to December 2016. Data of women who had eclampsia as defined by systolic blood pressure of $\geq 140 \mathrm{mmg}$, diastolic blood pressure of $90 \mathrm{mmHg}$, proteinuria of at least 2 plus and convulsions in patients with no background history of seizure disorder was collected and analysed. Meningitis and other causes of coma were excluded. Analysis of patient's age, occupation and educational status, booking status, parity, gestational age, symptoms observed prior to eclampsia, mode of delivery, types of complication, feto-maternal outcome and prognosis. Ethical approval was taken from the hospital authority. The data was collected from the labour ward medical record section and analyzed using simple percentages.

As a departmental protocol, all the patients were treated with magnesium sulphate according to the Pritchard regimen for controlling fit and anti-hypertensives (hydrallazine, nifedipine and methyldopa) were given for controlling hypertension. Nutrition and fluid balance were maintained.

Purpose of this study was to review all cases presenting in the department diagnosed as eclampsia, describe the current frequencies of eclampsia and study the feto-maternal outcome.
Table 1. Maternal characteristics and perinatal outcomes for gestations complicated by eclampsia.

\begin{tabular}{|c|c|c|}
\hline Variables & Numbers & Percentages \\
\hline \multicolumn{3}{|l|}{ AGES (YEARS) } \\
\hline$<19$ & 13 & $9.0 \%$ \\
\hline $20-24$ & 33 & $22.8 \%$ \\
\hline $25-29$ & 36 & $24.8 \%$ \\
\hline $30-34$ & 35 & $24.1 \%$ \\
\hline $35-39$ & 20 & $13.1 \%$ \\
\hline$>40$ & 8 & $5.5 \%$ \\
\hline \multicolumn{3}{|l|}{ PARITY } \\
\hline 0 & 58 & $40.0 \%$ \\
\hline $1-4$ & 47 & $32.4 \%$ \\
\hline$\geq 5$ & 40 & $27.6 \%$ \\
\hline \multicolumn{3}{|l|}{ EDUCATION } \\
\hline Primary & 79 & $54.5 \%$ \\
\hline Secondary & 39 & $26.9 \%$ \\
\hline Tertiary & 27 & $18.6 \%$ \\
\hline \multicolumn{3}{|l|}{ PLACE OF ANC } \\
\hline Unbooked & 86 & $59.3 \%$ \\
\hline JUTH & 12 & $8.3 \%$ \\
\hline Others & 47 & $32.4 \%$ \\
\hline \multicolumn{3}{|l|}{ Gestational age at delivery } \\
\hline$<37$ weeks & 79 & $54.5 \%$ \\
\hline$>37$ weeks & 66 & $45.5 \%$ \\
\hline \multicolumn{3}{|l|}{ Symptoms prior to eclampsia } \\
\hline Headache with blurring of vision & 106 & $73.1 \%$ \\
\hline Restlessness & 24 & $16.6 \%$ \\
\hline Nausea and vomiting & 9 & $6.2 \%$ \\
\hline Epigastric pain & 6 & $4.1 \%$ \\
\hline Maternal outcome Post partum hemorrhage & 12 & $8.3 \%$ \\
\hline Maternal death & 8 & $5.5 \%$ \\
\hline \multicolumn{3}{|l|}{ Mode of delivery } \\
\hline Caesarean section & 109 & $75.2 \%$ \\
\hline Vaginal delivery & 28 & $19.3 \%$ \\
\hline Instrumental vaginal delivery & 8 & $5.5 \%$ \\
\hline \multicolumn{3}{|l|}{ Fetal outcome Birth weights (kg) } \\
\hline$<2.5$ & 78 & $53.8 \%$ \\
\hline$>2.5$ & 67 & $46.2 \%$ \\
\hline Total live births & 127 & $87.6 \%$ \\
\hline Peri-natal death & 18 & $12.4 \%$ \\
\hline Babies with Low APGAR scores at 5minutes & 20 & $13.7 \%$ \\
\hline Babies admitted into SCBU & 24 & $16.6 \%$ \\
\hline \multicolumn{3}{|l|}{ Type of eclampsia } \\
\hline Ante-partum & 133 & $91.7 \%$ \\
\hline Post-partum & 12 & $8.3 \%$ \\
\hline
\end{tabular}

\section{Results}

There were seventeen thousand one hundred and sixty nine $(17,169)$ deliveries at Jos University Teaching Hospital, Jos Plateau State during the study period (2008-2016) and 145 $(0.84 \%)$ women presented with eclampsia.

Mean age was 26.9 years (17-44 years), majority of the parturients were above 20 years, 132 patients $(91.0 \%)$; while only 13 patients $(9.0 \%)$ were teenage mothers. With regards to parity, mean was $2.5(0-5)$. There was disparity in the distribution of the study population with nulliparas $58(40.0 \%)$ and multiparas $47(32.4 \%)$ and grand-multiparas accounting for $40(27.6 \%)$ of the patients.

Most of the patients presenting with eclampsia have primary education $79(54.5 \%)$, while those with secondary 
and tertiary education formed $26.9 \%$ and $18.6 \%$ respectively.

Most of the patents analysed did not book for ANC 86 $(59.3 \%), 12$ patients $(8.3 \%)$ booked for ANC in JUTH and others 47 (32.4\%) accounted for admissions from elsewhere (PHC's, General Hospitals and private clinics).

Headache with blurred vision was the commonest symptom prior to eclampsia in $73.1 \%$ of patients, followed by restlessness in $16.6 \%$, nausea and vomiting in $6.2 \%$ and epigastric pain in $4.1 \%$.

When feto-maternal outcomes were analyzed, the following were noticed; regarding the gestational ages of patients managed, 79 patients $(54.5 \%)$ were below 37 weeks of gestation and 66patients (45.5\%) were above 37 weeks of gestation. $78(53.8 \%)$ patients had low birth weight $(<2.5 \mathrm{~kg})$. 109 patients $(75.2 \%)$ underwent caesarean delivery, 28 patients, $(19.3 \%)$ had spontaneous vaginal delivery and 8 patients $(5.5 \%)$ had instrumental vaginal delivery. In this study $122(84.1 \%)$ babies were born alive, 79 babies $(54.5 \%)$ were born preterm (before 37 weeks of gestation), 17 of these babies $(14.0 \%)$ had neonatal asphyxia requiring SCBU admission and there were $23(15.9 \%)$ peri-natal deaths. 8 mothers died (case fatality rate 5.5\%) from complications of the disease and 12 women $(8.3 \%)$ had post partum hemorrhage.

Majority of the women had ante- partum eclampsia 133 (91.7\%), while post-partum eclampsia accounted for 12 $(8.3 \%)$ of the patients.

\section{Discussion}

The incidence of eclampsia varies from one geographical area of Nigeria to another. The incidence in the study population was $0.84 \%$ is similar to $0.80 \%$ reported in Aba [11] but is lower than that the 5.7\% reported in Nguru [9], 4.29\% in Sokoto [8], 2.52\% in Irrua [12], 1.3\% in Benin [20], 1.2\% in Kano [7] and $0.91 \%$ in Nnewi [10] and Ile-Ife [13] respectively. The mean age of eclamptic women in the study 26.9 years was similar to the reports from Benin [20], Nnewi [10] and Aba [12] where eclampsia occurred mostly in the 25-29 year group. The patients who are primigravidae constituted most of the women with eclampsia in the study with $40.9 \%$. This finding is similar to reports from Nnewi [10], Aba [12], Irrua [13], Ile-Ife [17] and Benin [20].

This study also shows that majority of patients $(59.3 \%)$ presenting with eclampsia had not booked for antenatal care. This is consistent with the findings in other centres in Nigeria $[7,9,10,12,13]$ where lack of quality antenatal care is identified in most patients with eclampsia. Reducing recognised obstacles to antenatal care attendance have been shown to favour the uptake of antenatal and maternity care, with positive impact on morbidity and mortality, including eclampsia.

The finding that majority of patients (91.7\%) had ante-partum eclampsia which is more than postpartum $(8.3 \%)$ is in support of reports from other centres in the country $[9,10$, 17]. This implies that prompt and proper management of the situation early on in the pregnancy or expedited referral to a tertiary center may help to improve feto-maternal outcome in the study population.

Majority of the patients were delivered via caesarean section $(75.2 \%)$ which is similarly supported by other studies $[10,12,13]$.

The case fatality rate in this study was $5.5 \%$ which is lower than the $8.0 \%$ reported in Ile-Ife [17], 10.7\% in Benin [20], $11.7 \%$ in Kano [7] and $22.97 \%$ in Irrua [12]. However, this is unacceptably higher than the maximum recommended $1 \%$ by the United Nations [25]. A decade before this current study, the case fatality rate for eclampsia was significantly higher with $22.3 \%$ [8] reported in the Northern part of the country. This can be attributed to the fact that diazepam was the anti-convulsant available for management of eclampsia. The improvement observed in this study may be as a result of intensive care management of eclampsia patients in the ICU and the administration of magnesium sulphate. However a lot more needs to be done to reduce high fatality rate in the environment.

The perinatal mortality rate of $12.4 \%$ reported in this study was lower than the $24.3 \%$ reported in Benin [20]. The use of magnesium sulphate could be a key contributor to the improved neonatal outcome seen in this study. This further stresses the benefit of magnesium sulphate for better neonatal outcome.

\section{Conclusion}

Effective management of pre-eclampsia/eclampsia is one of the signal functions of Emergency Obstetric and Newborn Care to prevent and promptly treat complications, avert maternal and newborn deaths and consequently contribute to the attainment of Millennium Development Goals (MDGs) 4 and 5 and to the post-2015 development agenda.

If it is desired to reduce the maternal and peri-natal mortality associated with eclampsia, efforts should be put to improve the socio economic condition, there is a great need for public health education expansion of education and training of personnel in the best professional techniques of maternal and neonatal care. When eclampsia is established, immediate hospitalization with best available nursing care and medical management with early termination of pregnancy should be done. If vaginal delivery is not anticipated shortly, caesarean section should be performed after correcting the haemo-dynamic status in best possible set up, only then the desired results can be achieved.

All the patients were treated with magnesium sulphate and this improved maternal and peri-natal outcome compared to other studies and most patients underwent caesarean section for delivery.

\section{References}

[1] WHO, UNICEF, UNFPA, The World Bank and the United Nations Population Division. 2014. Trends in Maternal Mortality: 1990 to 2013. ISBN 978924150722 6. CWorld Health Organization 2014. 
[2] Steegers EA, von Dadelszen P, Duvekot JJ, Pijnenborg R. Pre-eclampsia. The Lancet. 2010; 376 (9741): 631-644. doi: $10.1016 / \mathrm{S} 0140-6736$ (10) 60279-6.

[3] Packer CS. Biochemical markers and physiological parameters as indices for identifying patients at risk of developing pre-eclampsia. J Hypertens. 2005; 23 (1): 45-46. doi: 10.1097/00004872-200501000-00011.

[4] Brown MA, Hague WM, Higgins J, Lowe S, McCowan L, Oats $\mathrm{J}$, et al. The detection, investigation and management of hypertension in pregnancy: full consensus statement. Aust N Z J Obstet Gynaecol. 2000 May; 40 (2): 139-55.

[5] Sibai BM. Diagnosis and management of gestational hypertension and preeclampsia. Obstet Gynecol. 2003 Jul; 102 (1): $181-92$.

[6] Ujah IAO, Obi N, Mutihir JT, and Aisien OA. Seasonal pattern of Eclampsia in Northern Nigeria Trop J Obste Gynaecol, 2002; 19 (2): S19.

[7] Jido TA Eclampsia: maternal and fetal outcome Afr Health Sci. 2012 Jun; 12 (2): 148-52. doi: 10.4314/ahs.v12i2.11.

[8] Kullima AA, Kawuwa MB, Audu BM, Usman H, Geidam AD. A 5-year review of maternal mortality associated with eclampsia in a tertiary institution in northern Nigeria. Annal of African Medicine, 2009; 8 (2): 81-84.

[9] Tukur, J, Umar BA, Rabi'u A. Pattern of eclampsia in a tertiary health facility situated in a semi-rural town in northern Nigeria, 2007; 6 (4): 164-167.

[10] Adinma E. D Pattern of clinical presentation of eclampsia at Nnamdi Azikiwe University Teaching Hospital, Nnewi, Southeastern Nigeria. Niger J Med. 2012 Jul-Sep; 21 (3): 313-6.

[11] Onyearugha CN, Ugboma HA Fetal outcome of antepartum and intrapartum eclampsia in Aba, southeastern Nigeria. Trop Doct. 2012 Jul; 42 (3): 129-32. doi: 10.1258/td.2012.110206. Epub 2012 Apr 3.

[12] Okogbenin SA, Eigbefoh JO, Omorogbe F, Okogbo F, Okonta PI, Ohihoin AG. Eclampsia in Irrua Specialist Teaching Hospital: a five-year review. Niger J Clin Pract. 2010 Jun; 13 (2): $149-53$.

[13] Ade-Ojo IP, Loto OM. Outcome of eclampsia at the Obafemi Awolowo University Teaching Hospital Complex, Ile-Ife. Niger J Clin Pract. 2008 Sep; 11 (3): 279-84.
[14] World Health Organisation, author. A joint WHO/UNFPA/UNICEF and World bank statement. Geneva: WHO; 1999. Reduction of maternal mortality.

[15] WHO, UNICEF, UNFPA, World Bank Group \& the United Nations Population Division. (2015). Trends in Maternal Mortality: 1990 - 2015. Estimates by WHO, UNICEF, UNFPA, World Bank Group and the United Nations Population Division. Geneva: WHO.

[16] Population Council Nigeria, "Administering Magnesium Sulfate to Treat Severe Pre-eclampsia and Eclampsia," 2009, http://www.popcouncil.org/scripts/tellafriend.asp.

[17] Vigil-De Garcia P. Maternal death due to eclampia and HELLP syndrome. Int J Gynaecol Obstet. 2009; 97 (4): 90-94.

[18] Y. M Adamu, B. A Salihu, N. Sathiakumar, and R. Alexanderrt, Maternal mortality in Northern Nigeria: a population based study, Eur J Obstet Gynaecol Rep BioI, 109 (2003).

[19] Aboyeji A. P, Ijaiya M. A, and Fawole A. A, Maternal mortality in a Nigerian Teaching Hospital: a continuing tragedy, Trop Doct, 37 (2007), 83-85.

[20] S. O. Onuh and A. O. Aisien, Maternal and fetal outcome in eclamptic patients in Benin City, Nigeria, J Obstet Gynaecol, 2004 oct; 24 (7): 765-768.

[21] E. T. Agida, Adeka B. I, and K. A. Jibril, Pregnancy outcome in eclamptic at the University of Abuja Teaching Hospital, Gwagwalada, Abuja: A 3 years review, Niger j Chin Pract 13 (2010), 394-398.

[22] Young BC, Levine RJ, Karumanchi SA. Pathogenesis of preeclampsia. Annu Rev Pathol. 2010; 5: 173-92.

[23] Moodley J. Potentially increasing rates of hypertension in women of childbearing age and during pregnancy-be prepared! Cardiovasc J Afr. 2011 Dec; 22 (6): 330-4.

[24] Backes CH, Markham K, Moorehead P, Cordero L, Nankervis CA, Giannone PJ. Maternal preeclampsia and neonatal outcomes. J Pregnancy. 2011; 2011: 214365.

[25] A. Praxton, D. Maine, and D. Hijab, Using the UN process indicators of emergency obstetric services: questions and answers, Workbook, Averting Maternal Death \& Disability (AMDD) program 2003. 